\title{
Effect of Fermented Medicinal Plants (Gynura Procumbens, Rehmannia Glutinosa, Scutellaria Baicalensis) as Alternative Performance Enhancers in Broilers
}

\author{
Jin-Suk Jeong and In-Ho Kim \\ Department of Animal Resource and Science, Dankook University, \\ Cheonan, Choongnam, 330-714, Republic of Korea
}

\begin{abstract}
In the present study, the effect of dietary supplementation of mixed fermented medicinal plants (FMP) on growth performance in broilers and whether FMP have potential to serve as antibiotic growth promoter (AGP) alternatives was investigated. A total of 7651 -d-old male broiler chicks (ROSS strain) were used in a 5 wk feeding experiment and randomly divided into 5 groups with 9 replicates of 17 birds each. The treatments were NC (negative control, basal diet), PC (positive control, basal diet with 5 ppm enramycin), FMP 0.05 (basal diet with FMP 0.05\%), FMP 0.1 (basal diet with FMP 0.1\%), and FMP 0.2 (basal diet with FMP 0.2\%). Both body weight gain and feed conversion ratios were improved, as compared with NC or in response to FMP supplementation, respectively. Additionally, dry matter and nitrogen retention, metabolizable energy, and excreta noxious gas emission of ammonia, hydrogen sulfide, and total mercaptans were improved as compared with NC or in response to FMP supplementation, demonstrating a positive correlation. The amount of intestinal microflora was improved (increased Lactobacillus spp counts and reduced E.coli counts) as compared with NC, PC, and a dose response increase of FMP supplementation, in both the small and large intestines. Taken all together, our results suggest and support the viable possibility that FMPs supplementation can be used as an effective alternative to AGPs for improving the performance of broilers.
\end{abstract}

Key words: broiler, excreta noxious gas, fermented medicinal plants, growth performance, intestinal microflora

\section{Introduction}

Plants in the context of animal production are thought of as the principal nutrient source, and sometimes as an unwelcome source of anti-nutritional factors (ANFs) that interfere with an animal's utilization of ingested nutrients, since many of the ANFs are either toxic, unpalatable or undigestible. Otherwise, mainstream attitudes are changing, and over the last 15 years there has been growing interest in the use of plants and their extracts as alternative performance enhancers for animals (Greathead, 2003; Diarra et al., 2011). As a result of banning antibiotic supplementation to animal feed, additionally, natural alternatives, such as medicinal plants and herbs, have attracted widespread attention due to their wide range of potential beneficial effects and increasing industry demands for maximizing net returns and carcass quality (Jenkins and Atwal, 1995; Manesh et al., 2012).

Received: April 8, 2014, Accepted: October 11, 2014

Released Online Advance Publication: November 25, 2014

Correspondence: Prof. IH Kim, Department of Animal Resource and Science, Dankook University, Cheonan, Choongnam, 330-714, Republic of Korea. (E-mail: inhokim@dankook.ac.kr)
Gynura procumbens is a well-known tropical asian medicinal herbal plant, containing flavonoid sterol and steroid, as well as some proteins (Hew and Gam, 2010). Rehmannia glutinosa has been extensively used as a tonic for the blood in traditional Chinese medicine to protect to liver and show promise in relieving hepatitis (Zhang et al., 2008). Lastly, the genus Lamiaceae comprises over 360 species, many of which are medically important. Some Scutellaria baicalensis is used to treat neurological disorders, cancer, inflammatory diseases and viral and bacterial infections (Shang et al., 2010).

Patterson and Burkholder (2003) have proposed the use of probiotic micro-organisms as an alternative approach to subtherapeutic antibiotics in livestock. Probiotics can beneficially affect the animal by improving the properties of stimulating micro-organisms capable of modifying the gastrointestinal environment to favor health status and improve feed efficiency (Dierick, 1989; Edens, 2003). There is a need to find and determine more efficient alternatives or combinations of different alternatives for maintaining health and improving performance of broilers. To the best of our knowledge, the effects of dietary supplementa- 
tion of mixed fermented medicinal plants (FMP) obtained from exudates of Lactobacillus plantarum-fermented $G$. procumbens, Saccharomyses cereviseae-fermented R. glutinosa, and Bacillus licheniformis-fermented S. baicalensis as an alternative to antibiotic growth promoters (AGP) for broilers has yet to be investigated.

As such, the objective of this study was to investigate whether FMP could match or even surpass an AGP as a viable alternative. We determined the effects of dietary mixed FMP on the growth performance, nutrient retention, intestinal microflora, and excreta noxious gas emission of broilers as compared to basal diet and the AGP, enramycin, alone.

\section{Materials and Methods}

The experimental protocols used in this study were approved by the Animal Care and Use Committee of Dankook University (Anseodong, Cheonan, Choongnam, Korea).

\section{Preparation of Fermented Medicinal Plants}

The solid culture of the FMP product used in this study contained a mixture of lactic acid bacteria at $3.0 \times 10^{8} \mathrm{CFU} / \mathrm{g}$ (Lactobacillus planetarium species), yeasts at $7.5 \times 10^{7}$ $\mathrm{CFU} / \mathrm{g}$ (Saccharomyces cerevisiae species), and fermenting bacteria at $8.0 \times 10^{8} \mathrm{CFU} / \mathrm{g}$ (Bacillus licheniformis species). The following three medicinal plants were purchased from a traditional Chinese drug market in Korea. The FMP was prepared as follows: the upper leaves of the G. procumbens plant were taken and thoroughly washed, and then cut to approximately $1 \times 1 \mathrm{~cm}$ pieces. Processed leaves were mixed with $L$. plantarum NLRI1201 inoculants which were fermented under liquid condition with a similar amount of soybean meal $(1: 1, \mathrm{wt} / \mathrm{wt})$ in advance. The optimal condition for L. plantarum production was $40 \%$ moisture content for $2 \mathrm{~d}$ at $30^{\circ} \mathrm{C}$, under solid-state fermentation (SSF). To make the fermented $R$. glutinosa, these roots were thoroughly washed and then cut to approximately $1 \times 1 \mathrm{~cm}$ pieces. Processed roots were inoculated with $S$. cerevisiae 5\% (vol/wt) and then fermented for 2 months at low temperature. The optimal conditions for $R$. glutinosa production were $40 \%$ moisture content for $5 \mathrm{~d}$ at $25^{\circ} \mathrm{C}$ under SSF. The $S$. baicalensis roots were thoroughly washed and then cut to approximately $1 \times 1 \mathrm{~cm}$ pieces. Processed roots were inoculated with $B$. licheniformis DK42 5\% (vol/wt) and then fermented for 2 mon at low temperature. The optimal conditions for $S$. baicalensis production were $40 \%$ moisture content for $5 \mathrm{~d}$ at $30^{\circ} \mathrm{C}$ under SSF. Fresh fermented samples were dried at $50^{\circ} \mathrm{C}$ for $3 \mathrm{~d}$ and then granulating, which equal amounts of all three FMPs were mixed together as feeding additive.

\section{Experimental Design, Animals, Housing, and Diets}

A total of 765 1-d-old male broiler chicks (ROSS strain; BW 36.77 $\pm 0.33 \mathrm{~g}$ ) were used in an experimental feeding trial, lasting for up to $5 \mathrm{wk}$, and were allotted into 1 of 5 treatment groups in a completely random block design. Each dietary treatment consisted of 9 replicate cages, with 17 broilers per replicate, serving as a block. Dietary treatments included: 1) negative control (NC, basal diet), 2) positive control (PC, NC with 5 ppm enramycin), 3) FMP 0.05 (NC with FMP 0.05\%), 4) FMP 0.1 (NC with FMP 0.1\%), and 5) FMP 0.2 (NC with FMP $0.2 \%$ ). FMP was administrated by replacing the same amount of corn in the basal diet. The feeding program consisted of a starter diet until $3 \mathrm{wks}$ and a finisher diet until $5 \mathrm{wks}$, with the ingredients and calculated nutrient composition of the basal diet shown in Table 1. Diets were formulated to meet requirements by the NRC (1994) for broilers, and supplied in mash form. Water was provided ad libitum throughout the experimental period. All the chicks were kept in a battery brooder with three levels of stainless steel cages $(124 \mathrm{~cm}$ width $\times 64 \mathrm{~cm}$ length $\times 40 \mathrm{~cm}$ height), with 8 adjacent cages per level. Each cage was equipped with 2 drinker nipples and 2 open trough feeders. The temperature of the battery brooder was maintained at 33 $\pm 1^{\circ} \mathrm{C}$ during the 1 st week and subsequently decreased by $3^{\circ} \mathrm{C}$ per week until reaching a final temperature of $24^{\circ} \mathrm{C}$. Artificial light was provided $24 \mathrm{~h} / \mathrm{d}$ by the use of fluorescent lights.

\section{Sampling and Measurements}

Body weight gain (BWG) and feed intake (FI) were recorded on d 0, 2 wks, 4 wks, and at the end of the $5 \mathrm{wk}$ feeding trial, which was then used to calculate feed conversion ratio (FCR) after correcting for mortality. On d 35,9 broilers were randomly selected from each treatment (1 bird per cage) and blood samples were collected from the brachial vein into a sterile syringe. After collection, blood samples were aliquoted into both a vacuum (clot activator with gel) and $\mathrm{K}_{3}$ EDTA vacuum tube separately (Becton Dickinson Vacutainer Systems, Franklin Lakes, NJ, USA) and stored at $4^{\circ} \mathrm{C}$. Samples for serum analysis were then centrifuged at $3,000 \times \mathrm{g}$ for $15 \mathrm{~min}$, and then separated and stored at $4^{\circ} \mathrm{C}$. White blood cells (WBC), red blood cells (RBC), and lymphocyte percentages were analyzed using an automatic blood analyser (ADVIA 120, Bayer, Leverkusen, Germany). After blood collection, the same broilers were individually weighed and euthanized by cervical dislocation and exsanguinated. The breast muscle (pectoralis major), bursa of fabricius, liver, spleen, gizzard, and abdominal fat were then removed by trained personnel and weighed. Organ weights were expressed as a relative percentage to the whole body weight. The $\mathrm{pH}$ of the breast muscle sample was measured by a calibrated, glass-electrode $\mathrm{pH}$ meter (WTW pH 340-A, WTH Measurement Systems Inc., Ft. Myers, FL, USA). The breast muscle Hunter lightness $\left(\mathrm{L}^{*}\right)$, redness $\left(a^{*}\right)$, and yellowness $\left(b^{*}\right)$ values were determined using a Minolta CR410 chromameter (Konica Minolta Sensing Inc., Osaka, Japan). The water-holding capacity (WHC) was measured in accordance with the methods described by Kauffman et al. (1986). Briefly, $0.3 \mathrm{~g}$ sample was pressed at $3,000 \times \mathrm{g}$ for $3 \mathrm{~min}$ at $26^{\circ} \mathrm{C}$ on a $125 \mathrm{~mm}$ diameter piece of filter paper. The areas of the pressed sample and the expressed moisture were delineated and then determined using a digitizing area line sensor (MT-10S, M.T. Precision Co. Ltd., Tokyo, Japan). The ratio of water:meat area was then calculated, giving a measure of WHC (a smaller ratio in- 
dicates increased WHC). Drip loss was measured using approximately $2 \mathrm{~g}$ of heated sample according to the plastic bag method described by Honikel (1998). All samples were ground to pass through a $1 \mathrm{~mm}$ screen, after which they were determined for dry matter (DM, Method 930.15) and nitrogen (N, Method 984.13) retention, in accordance with the methods established by AOAC (1995). Broilers were fed diets mixed with chromic oxide $(0.2 \%)$ as an indigestible marker at $\mathrm{d} 5$ before excreta collection at wk 5. Excreta samples were collected for $3 \mathrm{~d}$, and then dried at $60^{\circ} \mathrm{C}$ for 72 $\mathrm{hr}$ and finely ground to pass through a $1 \mathrm{~mm}$ screen. DM and $\mathrm{N}$ retention was calculated from chromic oxide concentrations in the diets and excreta. Chromic oxide content were analyzed with UV absorption spectrophotometry (UV-1201, Shimadzu, Kyoto, Japan), as described by Fenton and Fenton (1979). N was determined using a Kjeltec 2300 analyzer (Foss Tecator AB, Hoeganaes, Sweden). Gross energy (GE) was measured by the heat of combustion in diet and fecal samples, respectively using a Parr 6100 oxygen bomb calorimeter (Parr instrument Co., Moline, IL, USA). Metabolizable energy (ME) was calculated as gross energy intake gross energy content of feces, and energy metabolizabilty (\%) was estimated to be (ME/GE $\times 100$ (Göranzan et al., 1983).

Small and large intestinal contents were collected into Qorpak glass containers $(118 \mathrm{~mL})$ under $\mathrm{CO}_{2}$, sealed, and placed on ice until transported to the laboratory for enumeration of microbial populations. These samples were assessed for populations of Lactobacilli and E.coli. One gram of composite excreta sample from each cage was diluted with $9 \mathrm{~mL}$ of $1 \%$ peptone broth (Becton Dickinson Vacutainer Systems) and then homogenized. Viable counts of bacteria in the fecal samples were then conducted by plating serial 10 -fold dilutions (in 1\% peptone solution) onto lactobacilli medium III agar plates (Medium 638; DSMZ, Braunschweig, Germany) and MacConkey agar plates (Difco Laboratories, Detroit, MI, USA) supplemented with glacial acetic acid $(1 \mathrm{~mL} / \mathrm{L})$ and mupirocin $(100 \mathrm{mg} / \mathrm{L})$ extracted from antimicrobial discs (Oxoid; Nepean, Ontario, Canada) to isolate the Lactobacilli and E. coli, respectively. The lactobacilli medium III agar plates were then incubated for $48 \mathrm{~h}$ at $37^{\circ} \mathrm{C}$ under anaerobic conditions, whereas MacConkey agar plates were incubated for $24 \mathrm{~h}$ at $37^{\circ} \mathrm{C}$. The microflora colonies were counted immediately after removal from the incubator, and concentration of microflora was finally expressed as $\log _{10}$ colony-forming units per gram of intestinal content.

Fresh excreta samples were collected from each cage on the last $2 \mathrm{~d}$ of the experiment and then mixed well for each respective cage. Analysis was then conducted using excreta samples $(300 \mathrm{~g})$ obtained from each cage that were stored in $2.6 \mathrm{~L}$ sealed plastic boxes. At $72 \mathrm{~h}$ post collection, the excreta samples were shaken manually for approximately 30 $\mathrm{s}$ in order to disrupt any crust formation on the surface of the sample and to homogenize the samples prior to measurement. The adhesive plaster was then punctured and $100 \mathrm{~mL}$ of headspace air was sampled approximately $2 \mathrm{~cm}$ above the surface. The boxes used for measuring the gas emission had a small hole in the middle of one side wall that ferment for a period of $24 \mathrm{~h}$ at room temperature $\left(25^{\circ} \mathrm{C}\right)$, after which the gas was sampled using a Gastec (model GV-100) gas sampling pump (Gastec Corp., Japan; Gastec detector tube No. $3 \mathrm{M}$ and $3 \mathrm{La}$ for ammonia; No. 4LL and $4 \mathrm{LK}$ for hydrogen sulfide; No. 70 and 70L for mercaptan).

\section{Statistical Analysis}

All experimental data were analyzed as a randomized complete block design using the GLM procedure of SAS (SAS Institute Inc., Cary, NC). Before conducting statistical analysis of the microbial counts, we performed a logarithmic conversion of the data. The cage was used as the experimental unit. Orthogonal contrasts were used to test the overall effect of growth promoting materials supplementation (NC vs. FMPs) and the effect of difference between of PC and FMPs (PC vs. FMPs), additionally, orthogonal comparison were conducted using polynomial regression to measure the linear and quadratic effects of increasing con-

Table 1. Ingredient and composition of the basal diet (as-fed basis) $^{1}$

\begin{tabular}{lrc}
\hline \multicolumn{1}{c}{ Ingredient (\%) } & Starter & Grower/Finisher \\
\hline Corn & 55.42 & 62.98 \\
Soybean meal (CP 48\%) & 28.25 & 24.61 \\
Corn gluten meal (CP 60\%) & 6.50 & 3.50 \\
Soybean oil & 5.50 & 4.89 \\
Dicalcium phosphate & 2.46 & 2.29 \\
Limestone & 0.89 & 0.75 \\
Salt & 0.20 & 0.20 \\
DL-Methionine (98\%) & 0.17 & 0.17 \\
L-Lysine-HCl (78\%) & 0.21 & 0.21 \\
Vitamin premix ${ }^{2}$ & 0.20 & 0.20 \\
Trace mineral premix & 0.20 & 0.20 \\
Total & 100.00 & 100.00 \\
\hline \multicolumn{1}{c}{ Chemical composition } & & \\
\hline ME, kcal/kg & 3,140 & 3200 \\
CP, \% & 22.00 & 20.09 \\
Lysine, \% & 1.10 & 0.41 \\
Met, \% & 0.54 & 0.93 \\
Met + Cys, \% & 0.93 & 0.87 \\
Ca, \% & 1.00 & 0.75 \\
Total P, \% & 0.80 & 5.87 \\
Crude Fat, \% & 4.32 & 6.21 \\
Crude Fiber, \% & 4.71 & \\
\hline
\end{tabular}

${ }^{1}$ The experimental diets were formulated by replacing soybean meal with 0 (negative control), $0.05 \%, 0.1 \%$, and $0.2 \%$ fermented medicinal plants extract.

${ }^{2}$ Provided per kg of complete diet: 15,000 IU of vitamin A, 3,750 IU of vitamin $\mathrm{D}_{3}, 37.5 \mathrm{mg}$ of vitamin $\mathrm{E}, 2.25 \mathrm{mg}$ of vitamin $\mathrm{K}_{3}, 3$ $\mathrm{mg}$ of thiamin, $7.5 \mathrm{mg}$ of riboflavin, $4.5 \mathrm{mg}$ of vitamin $\mathrm{B}_{6}, 24 \mathrm{ug}$ of vitamin $B_{12}, 51 \mathrm{mg}$ of niacin, $1.5 \mathrm{mg}$ of folic acid, $0.2 \mathrm{mg}$ of biotin and $13.5 \mathrm{mg}$ of Ca-Pantothenate.

${ }^{3}$ Provided per kg of complete diet: $\left.37.5 \mathrm{mg} \mathrm{Zn} \mathrm{(as} \mathrm{ZnSO}_{4}\right) ; 37.5$ $\left.\mathrm{mg} \mathrm{Mn} \mathrm{(as} \mathrm{MnO}_{2}\right) ; 37.5 \mathrm{mg} \mathrm{Fe}\left(\right.$ as $\left.\mathrm{FeSO}_{4} \cdot 7 \mathrm{H}_{2} \mathrm{O}\right) ; 3.75 \mathrm{mg} \mathrm{Cu}$ (as $\mathrm{CuSO}_{4} \cdot 5 \mathrm{H}_{2} \mathrm{O}$ ); $0.83 \mathrm{mg} \mathrm{I}$ (as $\mathrm{KI}$ ); and $0.23 \mathrm{mg} \mathrm{Se}\left(\right.$ as $\mathrm{Na}_{2} \mathrm{SeO}_{3}$. $\left.5 \mathrm{H}_{2} \mathrm{O}\right)$. 
Table 2. Effect of fermented medicinal plants (FMP) supplementation on growth performance in broilers ${ }^{1}$

\begin{tabular}{|c|c|c|c|c|c|c|c|c|c|c|}
\hline \multirow[b]{2}{*}{ Items $^{2}$} & \multirow[b]{2}{*}{$\mathrm{NC}$} & \multirow[b]{2}{*}{$\mathrm{PC}$} & \multirow[b]{2}{*}{ FMP 0.05} & \multirow[b]{2}{*}{ FMP 0.1} & \multirow[b]{2}{*}{ FMP 0.2} & \multirow[b]{2}{*}{$\mathrm{SEM}^{4}$} & \multicolumn{4}{|c|}{$P$-value } \\
\hline & & & & & & & $\begin{array}{l}\text { NC vs. } \\
\text { FMPs }\end{array}$ & $\begin{array}{l}\text { PC vs. } \\
\text { FMPs }\end{array}$ & Linear & Quadric \\
\hline \multicolumn{11}{|l|}{ Starter (0-2 wk) } \\
\hline BWG (g) & 413 & 412 & 419 & 420 & 419 & 13.91 & 0.3045 & 0.3754 & 0.3385 & 0.9188 \\
\hline FI (g) & 561 & 569 & 566 & 565 & 569 & 14.19 & 0.3047 & 0.7306 & 0.2268 & 0.5880 \\
\hline FCR & 1.359 & 1.375 & 1.353 & 1.347 & 1.359 & 0.049 & 0.7475 & 0.2747 & 0.9271 & 0.8352 \\
\hline \multicolumn{11}{|l|}{ Grower (3-4 wk) } \\
\hline BWG (g) & 876 & 869 & 897 & 909 & 940 & 74.58 & 0.2171 & 0.1734 & 0.0869 & 0.9007 \\
\hline FI $(g)$ & 1697 & 1708 & 1693 & 1693 & 1701 & 19.02 & 0.9101 & 0.1866 & 0.6085 & 0.9795 \\
\hline FCR & 1.945 & 1.972 & 1.903 & 1.872 & 1.817 & 0.147 & 0.1991 & 0.1132 & 0.0763 & 0.9864 \\
\hline \multicolumn{11}{|l|}{ Finisher (4-5 wk) } \\
\hline BWG (g) & 397 & 393 & 362 & 392 & 416 & 74.58 & 0.8479 & 0.9410 & 0.4843 & 0.5695 \\
\hline FI (g) & 480 & 484 & 468 & 471 & 486 & 24.64 & 0.6363 & 0.3614 & 0.6383 & 0.9700 \\
\hline FCR & 1.285 & 1.528 & 1.364 & 1.253 & 1.184 & 0.607 & 0.9431 & 0.3015 & 0.4424 & 0.6649 \\
\hline \multicolumn{11}{|l|}{ Overall } \\
\hline BWG (g) & 1681 & 1733 & 1663 & 1730 & 1779 & 56.63 & 0.0849 & 0.7216 & 0.0016 & 0.3114 \\
\hline FI $(\mathrm{g})$ & 2732 & 2754 & 2720 & 2731 & 2757 & 38.08 & 0.7871 & 0.3069 & 0.1481 & 0.9202 \\
\hline FCR & 1.628 & 1.590 & 1.636 & 1.580 & 1.552 & 0.057 & 0.1141 & 0.9860 & 0.0087 & 0.3585 \\
\hline
\end{tabular}

${ }^{1}$ Based on 765 birds with initial body weight of $36.8 \pm 0.33$. Each mean represented by 9 replications (17 birds/replication).

${ }^{2} \mathrm{BWG}$, body weight gain; FI, feed intake; FCR, feed conversion ratio.

${ }^{3} \mathrm{NC}$, negative control (basal diet); PC, positive control (basal diet +5 ppm enramycin); FMP 0.05, basal diet with $0.05 \%$ FMP extract; FMP 0.1 , basal diet with $0.1 \%$ FMP extract; FMP 0.2 , basal diet with $0.2 \%$ FMP extract.

${ }^{4}$ SEM: standard error of means.

Table 3. Effect of fermented medicinal plants (FMP) supplementation on nutrient retention and energy metabolizabilty in broilers ${ }^{1}$

\begin{tabular}{|c|c|c|c|c|c|c|c|c|c|c|}
\hline \multirow{2}{*}{$\begin{array}{l}\text { Treatment }^{2} \\
\text { Items }^{4}\end{array}$} & \multirow[b]{2}{*}{$\mathrm{NC}$} & \multirow[b]{2}{*}{$\mathrm{PC}$} & \multirow[b]{2}{*}{ FMP 0.05} & \multirow[b]{2}{*}{ FMP 0.1} & \multirow[b]{2}{*}{ FMP 0.2} & \multirow[b]{2}{*}{$\mathrm{SEM}^{3}$} & \multicolumn{4}{|c|}{$P$-value } \\
\hline & & & & & & & $\begin{array}{l}\text { NC vs. } \\
\text { FMPs }\end{array}$ & $\begin{array}{l}\text { PC vs. } \\
\text { FMPs }\end{array}$ & Linear & Quadric \\
\hline DM, \% & 73.26 & 74.62 & 74.83 & 74.66 & 76.30 & 1.483 & 0.0097 & 0.3717 & 0.0100 & 0.2546 \\
\hline $\mathrm{N}, \%$ & 62.71 & 63.01 & 63.71 & 65.06 & 65.32 & 1.909 & 0.0390 & 0.0764 & 0.0015 & 0.7567 \\
\hline \multicolumn{11}{|c|}{ Energy Metabolizability } \\
\hline$(\mathrm{ME} / \mathrm{GE}), \%$ & 72.21 & 73.35 & 73.73 & 74.33 & 73.01 & 1.647 & 0.0714 & 0.6689 & 0.3512 & 0.7374 \\
\hline
\end{tabular}

centrations of FMPs. Variability in the data was expressed as the pooled MSE, and $P<0.05$ was considered statistically significant, whereas $P<0.10$ was considered a tendency.

\section{Results}

\section{Growth Performance}

BWG improved in the overall period $(P=0.0849)$ as compared with NC. In addition, increased FMP supplementation demonstrated a linear improvement in the grower (linear, $P=0.0869$ ) and overall (linear, $P=0.0016$ ) periods, respectively (Table 2). However, there was no effect in the starter and finisher periods $(P>0.10)$. Furthermore, no significant effects of FMPs supplementation were observed on FI as compared with $\mathrm{NC}$ and $\mathrm{PC}$ treatments. However, FCR tended to decrease in the grower period (linear, $P=$ 0.0763 ) and significantly decreased during the overall period (linear, $P=0.0087$ ) in accordance with increased FMPs supplementation.

With regards to nutrient retention, FMP supplementation significantly improved DM $(P=0.0097$ and linear, $P=$ $0.0100)$ and $\mathrm{N}(P=0.0390$ and linear, $P=0.0015)$ retention, as compared with NC (Table 3). Furthermore, FMP supplementation also appears to improve $\mathrm{ME}(P=0.0714)$ as compared with NC.

\section{Meat Quality and Relative Organ Weight}

Broilers fed the FMP supplemental diet did not signifi- 
Table 4. Effect of fermented medicinal plants (FMP) supplementation on meat quality and visceral organ weight in broilers $^{1}$

\begin{tabular}{|c|c|c|c|c|c|c|c|c|c|c|}
\hline \multirow[b]{2}{*}{ Items $^{2}$} & \multirow[b]{2}{*}{$\mathrm{NC}$} & \multirow[b]{2}{*}{$\mathrm{PC}$} & \multirow[b]{2}{*}{ FMP 0.05} & \multirow[b]{2}{*}{ FMP 0.1} & \multirow[b]{2}{*}{ FMP 0.2} & \multirow[b]{2}{*}{$\mathrm{SEM}^{4}$} & \multicolumn{4}{|c|}{$P$-value } \\
\hline & & & & & & & $\begin{array}{l}\text { NC } v s . \\
\text { FMPs }\end{array}$ & $\begin{array}{l}\text { PC } v s . \\
\text { FMPs }\end{array}$ & Linear & Quadric \\
\hline $\mathrm{pH}$ value & 5.44 & 5.43 & 5.48 & 5.52 & 5.52 & 0.155 & 0.3972 & 0.3285 & 0.5064 & 0.8992 \\
\hline \multicolumn{11}{|l|}{ Breast muscle color } \\
\hline $\mathrm{L}^{*}$ & 54.87 & 55.64 & 56.24 & 55.15 & 56.20 & 2.823 & 0.4623 & 0.8721 & 0.6018 & 0.4113 \\
\hline$a^{*}$ & 13.75 & 14.32 & 14.17 & 13.79 & 13.15 & 2.085 & 0.9655 & 0.5398 & 0.5239 & 0.8727 \\
\hline$b^{*}$ & 14.94 & 15.31 & 14.81 & 15.18 & 15.86 & 1.761 & 0.6853 & 0.9776 & 0.2799 & 0.9466 \\
\hline WHC, $\%$ & 62.05 & 63.05 & 63.46 & 61.54 & 63.59 & 3.351 & 0.4572 & 0.9050 & 0.8162 & 0.1268 \\
\hline \multicolumn{11}{|l|}{ Drip loss, $\%$} \\
\hline $1 d$ & 2.43 & 2.34 & 2.63 & 2.63 & 2.66 & 0.503 & 0.3748 & 0.2135 & 0.4445 & 0.8012 \\
\hline $3 d$ & 5.28 & 5.02 & 5.27 & 5.05 & 5.30 & 0.646 & 0.8232 & 0.5434 & 0.9066 & 0.5668 \\
\hline $5 \mathrm{~d}$ & 8.22 & 8.01 & 7.92 & 8.23 & 8.33 & 0.944 & 0.8861 & 0.7425 & 0.7428 & 0.6651 \\
\hline $7 \mathrm{~d}$ & 10.84 & 10.39 & 10.32 & 10.76 & 10.48 & 0.854 & 0.4386 & 0.7521 & 0.6737 & 0.2681 \\
\hline \multicolumn{11}{|c|}{ Visceral organ weight, $\mathrm{g} / \mathrm{kg}$ live weight } \\
\hline Liver & 19.91 & 20.99 & 20.07 & 21.09 & 20.99 & 0.355 & 0.4283 & 0.7859 & 0.2498 & 0.5877 \\
\hline Spleen & 1.18 & 1.07 & 1.12 & 1.02 & 1.05 & 0.031 & 0.1350 & 0.8951 & 0.1124 & 0.5665 \\
\hline Bursa of fabricius & 1.18 & 1.32 & 1.21 & 1.22 & 1.19 & 0.050 & 0.8575 & 0.4069 & 0.9873 & 0.9305 \\
\hline Breast muscle & 91.79 & 89.53 & 92.03 & 91.18 & 92.60 & 0.939 & 0.9523 & 0.2289 & 0.9433 & 0.7951 \\
\hline Abdominal fat & 12.07 & 11.65 & 12.40 & 12.72 & 12.56 & 0.285 & 0.5019 & 0.2061 & 0.5650 & 0.8399 \\
\hline Gizzard & 12.03 & 11.95 & 11.83 & 12.18 & 13.08 & 0.194 & 0.5318 & 0.4359 & 0.0383 & 0.9723 \\
\hline
\end{tabular}

${ }^{1}$ Each mean represented by 9 replications.

${ }^{2} \mathrm{~L}^{*}$, lightness; $\mathrm{a}^{*}$, redness, $\mathrm{b}^{*}$, yellowness, WHC, water holding capacity.

${ }^{3} \mathrm{NC}$, negative control (basal diet); PC, positive control (basal diet +5 ppm enramycin); FMP 0.05, basal diet with 0.05\% FMP extract; FMP 0.1, basal diet with $0.1 \%$ FMP extract; FMP 0.2, basal diet with $0.2 \%$ FMP extract.

${ }^{4}$ SEM: standard error of means.

Table 5. Effect of fermented medicinal plants (FMP) supplementation on blood profiles in broilers ${ }^{1}$

\begin{tabular}{|c|c|c|c|c|c|c|c|c|c|c|}
\hline \multirow[b]{2}{*}{ Items $^{2}$} & \multirow[b]{2}{*}{$\mathrm{NC}$} & \multirow[b]{2}{*}{$\mathrm{PC}$} & \multirow[b]{2}{*}{ FMP 0.05} & \multirow[b]{2}{*}{ FMP 0.1} & \multirow[b]{2}{*}{ FMP 0.2} & \multirow[b]{2}{*}{$\mathrm{SEM}^{4}$} & \multicolumn{4}{|c|}{$P$-value } \\
\hline & & & & & & & $\begin{array}{l}\text { NC vs. } \\
\text { FMPs }\end{array}$ & $\begin{array}{l}\text { PC vs. } \\
\text { FMPs }\end{array}$ & Linear & Quadric \\
\hline $\mathrm{WBC}, 10^{3} / \mu \mathrm{l}$ & 30.2 & 30.8 & 30.9 & 30.8 & 30.7 & 11.43 & 0.3265 & 0.9473 & 0.5995 & 0.7402 \\
\hline $\mathrm{RBC}, 10^{6} / \mu \mathrm{l}$ & 1.95 & 2.04 & 2.03 & 2.06 & 2.03 & 0.144 & 0.1924 & 0.9807 & 0.2565 & 0.9945 \\
\hline LYM, \% & 81.7 & 79.2 & 84.5 & 78.7 & 79.2 & 4.98 & 0.7090 & 0.5004 & 0.1971 & 0.1489 \\
\hline
\end{tabular}

${ }^{1}$ Each mean represented by 9 replications.

${ }^{2}$ WBC, white blood cell; RBC, red blood cell; LYM, lymphocyte.

${ }^{3} \mathrm{NC}$, negative control (basal diet); PC, positive control (basal diet +5 ppm enramycin); FMP 0.05, basal diet with 0.05\% FMP extract; FMP 0.1, basal diet with $0.1 \%$ FMP extract; FMP 0.2 , basal diet with $0.2 \%$ FMP extract.

${ }^{4}$ SEM: standard error of means.

cantly differ in breast muscle color $\left(\mathrm{L}^{*}, \mathrm{a}^{*}\right.$, and $\left.\mathrm{b}^{*}\right)$ or $\mathrm{pH}$ value as compared with those fed NC and PC treatments $(P$ $>0.10$ ) (Table 4). Additionally, no significant differences were observed in WHC, drip loss, and visceral organ weights between treatments, except for the gizzard, which demonstrated a linear improvement in weight gain (linear, $P=$ 0.0383) with increasing FMP amount supplementation.

\section{Blood Profiles}

FMPs supplementation did not affect $\mathrm{RBC}, \mathrm{WBC}$, and lymphocyte percentages in the current study $(P>0.10)$ (Table 5).
Intestinal Microflora and Excreta Noxious Gas Emission

FMP supplementation increased Lactobacilli counts in the small $(P=0.0243, P=0.0296$, and linear, $P=0.0014)$ and large intestines $(P=0.0030, P=0.0032$, and linear, $P=$ $0.0034)$ as compared with NC or PC and in accordance with increasing amount of FMP, respectively (Table 6). Furthermore, E. coli counts were reduced in the small $(P=$ $0.0151)$ and large intestines $(P<0.0001)$ as compared with NC. However, no differences were observed in E. coli counts when compared with PC (small intestine, $P=0.2821$; large intestine, $P=0.2995)$. Nonetheless, FMP supplementation was significant in both small $(P=0.0350)$ and large 
Table 6. Effect of fermented medicinal plants (FMP) supplementation on small and large intestinal microflora in broilers $^{1}$

\begin{tabular}{|c|c|c|c|c|c|c|c|c|c|c|}
\hline \multirow[t]{2}{*}{ Treatment $^{2}$} & \multirow[b]{2}{*}{$\mathrm{NC}$} & \multirow[b]{2}{*}{$\mathrm{PC}$} & \multirow[b]{2}{*}{ FMP 0.05} & \multirow[b]{2}{*}{ FMP 0.1} & \multirow[b]{2}{*}{ FMP 0.2} & \multirow[b]{2}{*}{$\mathrm{SEM}^{3}$} & \multicolumn{4}{|c|}{$P$-value } \\
\hline & & & & & & & $\begin{array}{l}\text { NC vs. } \\
\text { FMPs }\end{array}$ & $\begin{array}{l}\text { PC vs. } \\
\text { FMPs }\end{array}$ & Linear & Quadric \\
\hline \multicolumn{11}{|c|}{ Small intestine $\left(\log _{10} \mathrm{CFU} / \mathrm{g}\right)$} \\
\hline Lactobacillus & 7.56 & 7.57 & 7.59 & 7.67 & 7.73 & 0.089 & 0.0243 & 0.0296 & 0.0014 & 0.7009 \\
\hline E. coli & 6.45 & 6.33 & 6.37 & 6.39 & 6.34 & 0.069 & 0.0151 & 0.2821 & 0.0350 & 0.2460 \\
\hline \multicolumn{11}{|c|}{ Large intestine $\left(\log _{10} \mathrm{CFU} / \mathrm{g}\right)$} \\
\hline Lactobacillus & 8.01 & 8.01 & 8.04 & 8.05 & 8.08 & 0.029 & 0.0030 & 0.0032 & 0.0034 & 0.3589 \\
\hline E. coli & 7.02 & 6.90 & 6.91 & 6.85 & 6.83 & 0.065 & $<.0001$ & 0.2995 & $<.0001$ & 0.9908 \\
\hline
\end{tabular}

${ }^{1}$ Each mean represented by 9 replications.

${ }^{2} \mathrm{NC}$, negative control (basal diet); PC, positive control (basal diet + 5 ppm enramycin); FMP 0.05, basal diet with 0.05\% FMP extract; FMP 0.1,

basal diet with $0.1 \%$ FMP extract; FMP 0.2 , basal diet with $0.2 \%$ FMP extract.

${ }^{3}$ SEM: standard error of means.

Table 7. Effect of fermented medicinal plants (FMP) supplementation on fecal noxious gas emission in broilers ${ }^{1}$

\begin{tabular}{|c|c|c|c|c|c|c|c|c|c|c|}
\hline \multirow[b]{2}{*}{ Items, ppm } & \multirow[b]{2}{*}{$\mathrm{NC}$} & \multirow[b]{2}{*}{$\mathrm{PC}$} & \multirow[b]{2}{*}{ FMP 0.05} & \multirow[b]{2}{*}{ FMP 0.1} & \multirow[b]{2}{*}{ FMP 0.2} & \multirow[b]{2}{*}{$\mathrm{MSE}^{3}$} & \multicolumn{4}{|c|}{$P$-value } \\
\hline & & & & & & & $\begin{array}{l}\text { NC vs. } \\
\text { FMPs }\end{array}$ & $\begin{array}{l}\text { PC vs. } \\
\text { FMPs }\end{array}$ & Linear & Quadric \\
\hline Ammonia & 83.1 & 79.9 & 79.6 & 75.3 & 74.8 & 5.46 & 0.0199 & 0.2148 & 0.0059 & 0.6276 \\
\hline Hydrogen sulfide & 33.3 & 33.0 & 32.6 & 31.9 & 30.5 & 2.09 & 0.1188 & 0.1892 & 0.0313 & 0.9017 \\
\hline Total mercaptans & 12.4 & 12.1 & 12.2 & 11.9 & 11.2 & 0.92 & 0.1747 & 0.4370 & 0.0467 & 0.9858 \\
\hline
\end{tabular}

intestines $(P=<0.0001)$ in accordance with increasing amount of FMP.

The effect of FMP supplementation on the emission of ammonia, hydrogen sulfide, and total mercaptans is shown in Table 7. FMPs supplementation significantly reduced ammonia emission $(P=0.0199)$ as compared with NC. Additionally, ammonia (linear, $P=0.0059$ ), hydrogen sulfide (linear, $P=0.0313$ ), and total mercaptans (linear, $P=0.0467$ ) was significantly reduced in accordance with increasing FMP supplementation.

\section{Discussion}

In the current study, significant improvements to BWG and FCR were observed during the overall period as a result of dietary supplementation with FMP. Unfortunately, there are currently no available studies, focusing on the influence of feeding diets supplemented with mixed FMP to broilers to compare against. However, there are other studies reporting on the use of other fermented plant extracts, similar to the FMP used in this study, as food supplementation in broilers. Lokaewmanee et al. (2012) reported improved BWG and FCR in broilers with an increase in fermented fruit and vegetable products consumption as compared to $\mathrm{NC}$ treatment at $49 \mathrm{~d}$ of age. In addition, Kassie (2009) observed improvement in BWG and FCR, after feeding chicks with
100 ppm essential oils, derived from thyme and cinnamon, as compared to NC treatment. Meanwhile, Ao et al. (2011a, 2011b) reported no significant effect on BWG and FCR throughout the overall period, in broilers fed with up to 4 $\mathrm{g} / \mathrm{kg}$ fermented garlic powder and red ginseng extract as compared with NC treatment. Khonyoung et al. (2012) also concluded that $1 \%$ dried fermented ginger treatment did not affect BWG and FCR, throughout the overall period, as compared with NC treatment. These contradictory results observed, amongst many studies, may be due to differences in the quality, as well as the quantity of active chemicals derived from plant extracts, which will determine and influence broiler response.

Our results showed that FMP derived from G. procumbens, $R$. glutinosa, and $S$. baicalensis in broiler diets significantly improved BWG and FCR, which may be due to bioactive chemicals (peroxidase, osmotin-like protein, thaumatin-like protein (Hew and Gam, 2010); catalpol, mannit, mannitol, stachyose (Zhang et al., 2008); baicalein, baicalin, wogonin, wogonoside (Shang et al., 2010), found in medicinal plants. Furthermore, the fermentation process used in the current study improved 1) the extraction quantity of active materials derived from medicinal plants from $40-50 \%$ to $90 \%$, due to leaves processing rendering smaller particles for microbial digestion (Kim et al., 2012), and 2) 
nutrient utilization and retention resulting from favourable manipulations to the digestive and absorptive processes of the intestine in poultry (Yazdankish et al., 2010). Consequently, these effects originate from the interaction of complex active chemicals derived from FMP. However, the exact growth promoting mechanisms of medicinal plants in broilers is still poorly understood. Perhaps, in future studies which will examine individual medicinal plants, we might be able to elucidate the specific contribution and effect of each plant component of the mixed FMP used in our current study.

Supplementation with FMP lead to increased Lactobacilli and reduced $E$. coli counts as compared with $\mathrm{NC}$ treatment, and increased Lactobacilli counts as compared to PC treatment. These results corroborate with results from Jamroz (2005) who reported that broilers fed a diet supplemented with plant extracts consisting of capsaicin, cinnamaldehyde, and carvacrol demonstrated reduced $E$. coli and increased Lactobacilli counts as compared to control diet. Annuk (2003) and Tucker (2002) have reported that medicinal plant extracts may be able to affect the cell surface hydrophobicity of microbes, which in turn may affect their adhesion/binding capacity to host tissue, which may have resulted in the observed reduction in E. coli counts. Alterations to the bacterial cell surface may be mediated via two possible mechanisms: 1) medicinal plant extracts may modulate the permeability of the cytoplasmic membrane, resulting in loss of chemiosmotic control of the affected cell, leading to cell death (Cox et al., 2000), and 2) monoterpenes, derived from plant extracts, can cross the lipid bilayer, penetrating the cell and interacting at specific sites, exerting their antimicrobial activity intracellularly (Brenes and Roura, 2010). Based on the results of the present study, it may be considered that the peculiar bioactive chemicals derived from medicinal plant and microflora grown under a fermented plants matrix may modulate synergistically by suppressing intestinal harmful microflora while concomitantly favoring beneficial microflora, thereby ultimately enhancing overall gut health (Fuller, 1989; Kim et al., 2007).

FMP supplementation leads to increased and improved $\mathrm{DM}$ and $\mathrm{N}$ retention, as compared with $\mathrm{NC}$ treatment, in addition to increased DM retention as compared to PC treatment. Our study indicates that FMP supplementation can be more effective than PC (enramycin) treatment at modulating the gastrointestinal environment and subsequent nutrient utilization in broilers. Hernandez et al. (2004) demonstrated that supplementation of plant extracts consisting of carvacrol, cinnamaldehyde, and capsaicin improved apparent fecal digestibility of DM and CP of the broiler diet. Garcia et al. (2007) also observed that finisher broiler diets supplemented with a mixture of sage, thyme, and rosemary or with a commercial product containing capsaicin, cinnamaldehyde, and carvacrol resulted in similar ileal DM and $\mathrm{N}$ digestibilities as the diet supplemented with antibiotic, and was significantly higher overall than the control diet. It may be considered that plant extracts may stimulate the production of saliva, and favor pancreatic and intestinal origin enzyme secretion, improving nutrient digestibility (Platel and
Srinivasan, 2004). In addition, the plant matrix may contain different molecules that have intrinsic bioactivities on animal physiology and metabolism, similar to prebiotics (Dorman and Deans, 2000).

The shift of excreta fecal microbial composition by FMP $0.2 \%$ supplementation was followed by a reduction in excreta ammonia, hydrogen sulfide, and mercaptans gas emission as compared with $\mathrm{NC}$ treatment and a reduction in excreta hydrogen sulfide gas emission as compared with PC treatment. Excreta noxious gas emission has been suggested to be related to nutrient utilization and the intestinal microbial ecosystem (Ferket et al., 2002). As such, alterations to the intestinal microbial population may have relevant and important implications on reducing excreta noxious gas emissions. Our results indicate that FMP supplementation in broilers reduced excreta ammonia and hydrogen sulfide gas emission, which is consistent with the findings of Sung (2013) and Ra et al. (2004) who reported that fermented phytogenics, prepared by fermented functional herbs with probiotics, have the ability for reducing excreta noxious gas emission. Additionally, Chiand and Hsieh (1995) and Zhang and Kim (2013) reported that probiotics can improve dietary protein digestibility, thereby indirectly reducing excreta $\mathrm{N}$ content.

In conclusion, the results of our study indicate that FMPs can be used as a possible viable alternative to AGP in feeding broilers, while obtaining most of the same benefits without any of the negative associated with an AGP. In addition, the source of FMP, which included 3 different microorganism (L. plantarum, S. cereviseae, and B. licheniformis) and 3 different types of medicinal plants ( $G$. procumbens, $R$. glutinosa, and $S$. baicalensis), can be a major factor in explaining any variation observed when producing batches of FMPs. In further studies, we plan to test and compare individual FMPs and combinations thereof, used in this study, to determine the effect of each type of plant alone.

\section{References}

Annuk H, Shchepetova J, Kullisaar T, Songisepp E, Zilmer M and Mikelsaar M. Characterization of intestinal lactobacilli as putative probiotic candidates. Journal of Applied Microbiology, 94: 403-412. 2003.

Ao X, Yoo JS, Zhou TX, Wang JP, Meng QW, Yen L, Cho JH and Kim IH. Effects of fermented garlic powder supplementation on growth performance, blood profiles and breast meat quality in broilers. Livestock Science, 141: 85-89. 2011a.

Ao X, Zhou TX, Kim HJ, Hong SM and Kim IH. Influence of fermented red ginseng extract on broilers and laying hens. Asian-Australasian Journal of Animal Sciences, 24: 993-1000. 2011b.

AOAC. Official Method of Analysis, $16^{\text {th }}$ Edition. Association of Office Analytical Chemists, Washington, D.C 1995.

Brenes A and Roura E. Essential oils in poultry nutrition: main effects and modes of action. Animal Feed Science and Technology, 158: 1-14. 2010.

Chiang S and Hsiem W. Effect of direct feed microorganism on broiler growth performance and litter ammonia level. AsianAustralasian Journal of Animal Sciences, 8: 159-162. 1995. 
Cox SD, Mann CM, Markham JL, Bell HC, Gustafson JE, Warmington JR and Wyllies SG. The mode of antimicrobial action of the essential oil of Melaleuca alternifolia (tea tree oil). Journal of Applied Microbiology, 88: 170-175. 2000.

Diarra SS, Kwari ID, Girgiri YA, Saleh YA and Igwebuike JU. The use of sorrel (Hibiscuss sabdariffa) seed as a feed ingredient for poultry: A review. Research Opinions in Animal \& Veterinary Sciences, 1: 573-577. 2011.

Dierick NA. Biotechnology aids to improve feed and feed digestion: enzymes and fermentation. Archives of Animal Nutrition, 39: 241-261. 1989.

Dorman HJD and Deans SG. Antimicrobial agents from plants: antibacterial activity of plant volatile oils. Journal of Applied Microbiology, 88: 308-316. 2000.

Edens FW. An alternative for antibiotic use in poultry: probiotics. Revista Brasileira de Ciencia Avicola, 5: 75-97. 2003.

Fenton TW and Fenton M. An improved method for chromic oxide determination in feed and feces. Canadian Journal of Animal Science, 59: 631-634. 1979.

Ferket PR, van Heugten E, van Kempen TATG and Angel R. Nutritional strategies to reduce environmental emissions from nonruminants, Journal of Animal Science, 80: 168-182. 2002.

Fuller R. Probiotics in man and animals. Journal of Applied Bacteriology, 66: 365-378. 1989.

Garcia V, Catala-Gregori P, Hernandez F, Megias MD and Madrid J. Effect of formic acid and plant extracts on growth, nutrient digestibility, intestine mucosa morphology and meat yield of broilers. Journal of Applied Poultry Research, 16: 555-562. 2007.

Göranzon H, Forsum E, Thilén M. Calculation and determination of metabolizable energy in mixed diets to humans. American Journal of Clinical Nutrition, 38: 954-963. 1983.

Greathead H. Plants and plant extracts for improving animal productivity. Proceedings of the Nutrition Society, 62: 279-290. 2003.

Hernandez F, Madrid J, Garcia V, Orengo J and Megias MD. Influence of two plant extracts on broilers performance, digestibility, and digestive organ size. Poultry Science, 83: 169174. 2004.

Hew CS and Gam LH. Proteome analysis of abundant proteins extracted from the leaf of Gynura procumbens. Applied Biochemistry and Biotechnology, 165: 1577-1586. 2010.

Honikel KO. Reference methods for the assessment of physical characteristic of meat. Meat Science, 49: 447-457. 1998.

Jamroz D, Wiliczkiewicz A, Wertelecki T, Orda J and Skorupinska J. Use of active substances of plant origin in chicken diets based on maize and locally grown cereals. British Poultry Science, 46: 485-493. 2005.

Jenkins KJ and Atwal AS. Flavonoids increase tissue essential fatty acids in vitamin $\mathrm{E}$ deficient chicks. Journal of Nutritional Biochemistry, 6: 97-103. 1995.

Kassie GAM. Influence of two plant extracts derived from thyme and cinnamon on broiler performance. Pakistan Veterinary Journal, 29: 169-173. 2009.

Kauffman RG, Eikelenboom G, van der Wal PG, Engel B and Zaar M. A comparison of methods to estimate water-holding capacity in post-rigor porcine muscle. Meat Science, 18: 307-322. 1986.
Khonyoung D, Yamauchi K, Buwjoom T, Maneewan B and Thongwittaya N. Effects of dietary dried fermented ginger on growth performance, carcass quality, and intestinal histology of heat-stressed broilers. Canadian Journal of Animal Science, 92: 307-317. 2012.

Kim DW, Kim SH, Yu DJ, Kang GH, Kim JH, Kang HG, Jang BG, Na JC, Suh OS, Jang IS and Lee KH. Effects of single or mixed supplements of plant extract, fermented medicinal plants and Lactobacillus on growth performance in broilers. Korean Journal of Oriental Physiology \& Pathology, 34: 187-196. 2007.

Kim EH, Kim KS, Chae SK, Kim BS and Kang JS. Comparison of biological activities on Rehmanniae radix and fermented Rehmanniae radix. Korean Journal of Oriental Physiology \& Pathology, 26: 306-313. 2012.

Lokaewmanee K, Yamauchi K and Thongwittaya N. Effects of fermented plant product on growth performance, some blood variables, carcase characteristics, and intestinal histology in broilers. British Poultry Science, 53: 215-223. 2012.

Manesh MK, Kazemi S and Asfari M. Influence of poly germander (Teucrium polium) and watercress (Nasturtium officinale) extract on performance, carcass quality and blood metabolites of male broilers. Research Opinions in Animal \& Veterinary Sciences, 2: 66-68. 2012.

National Research Council. Nutrient requirement of poultry, 9th ed. National Research Council, National academy press, Washington, D.C. 1994.

Patterson JA and Burkholder KM. Application of prebiotics and probiotics in poultry production. Poultry Science, 82: 627631. 2003.

Platel K and Srinivasan K. Digestive stimulant action of spices: a myth or reality? Indian Journal of Medical Research, 119: 167-179. 2004.

Ra JC, Han HJ and Song JE. Effect of probiotics on production and improvement of environment in pigs and broilers. Korean Journal of Veterinary Public Health, 28: 157-167. 2004

SAS Institute. SAS user's guide, Release 9.2 edition. SAS Institute Inc., Cary NC. USA. 2003.

Shang X, He X, Li M, Zhang R, Fan P, Zhang Q and Jia Z. The genus Scutellaria an ethnopharmacological and phytochemical review. Journal of Ethnopharmacology, 128: 279-313. 2010.

Sung HG. Effects of fermented phytogenics on fecal odour and performance in laying hens. Annals of Animal Resource Sciences, 24: 29-37. 2013.

Tucker LA. 2002. Plant extracts to maintain poultry performance. Feed International, 23: 26-29.

Yazdankish R, Mirzadeh, KH and Bojarpoor M. Effect of probiotic (protexin) on immune response and carccas performance of broilers. Msc. Thesis. Ramin University, Iran. pp, 57-79. 2010.

Zhang RX, Li MX and Jia ZP. Rehmannia glutinosa: Review of botany, chemistry, and pharmacology. Journal of Ethnopharmacology, 117: 199-214. 2008.

Zhang ZF and Kim IH. Effects of probiotic supplementation in different energy and nutrient density diets on performance, egg quality, excreta microflora, excreta noxious gas emission, and serum cholesterol concentrations in laying hens. Journal of Animal Science, 91: 4781-4787. 2013. 